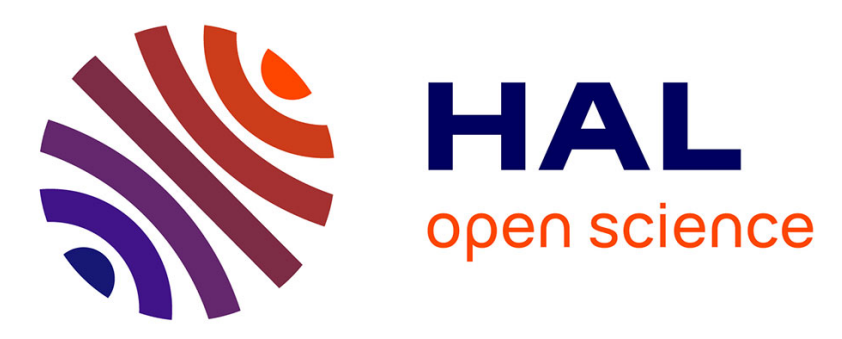

\title{
Causes for the recent increase in sea surface salinity in the north-eastern Gulf of Guinea
}

Casimir Y. Da-Allada, Gaël Alory, Yves Du Penhoat, Julien Jouanno, Norbert Mahouton Hounkonnou, Élodie Kestenare

\section{- To cite this version:}

Casimir Y. Da-Allada, Gaël Alory, Yves Du Penhoat, Julien Jouanno, Norbert Mahouton Hounkonnou, et al.. Causes for the recent increase in sea surface salinity in the north-eastern Gulf of Guinea. African Journal of Marine Science, 2014, 36 (2), pp.197-205. 10.2989/1814232X.2014.927398 . hal-01291894

\section{HAL Id: hal-01291894 \\ https://hal.science/hal-01291894}

Submitted on 22 Mar 2016

HAL is a multi-disciplinary open access archive for the deposit and dissemination of scientific research documents, whether they are published or not. The documents may come from teaching and research institutions in France or abroad, or from public or private research centers.
L'archive ouverte pluridisciplinaire HAL, est destinée au dépôt et à la diffusion de documents scientifiques de niveau recherche, publiés ou non, émanant des établissements d'enseignement et de recherche français ou étrangers, des laboratoires publics ou privés. 
1 Causes for the Recent Increase in Sea Surface Salinity in the north-eastern

$16{ }^{1}$ International Chair in Mathematical Physics and Applications (ICMPA - UNESCO Chair);

17 Université d'Abomey-Calavi, 072 BP 50 Cotonou, Bénin

$18{ }^{2}$ Université de Toulouse; UPS (OMP); LEGOS; 14 Av, Edouard Belin, F-31400 Toulouse,

19 France

$20 \quad{ }^{3}$ IRD, LEGOS, Toulouse, France

$21{ }^{4}$ IRHOB, 08 BP 841 Cotonou, Bénin

$22{ }^{5}$ CNAP, LEGOS, Toulouse, France

$23 \quad{ }^{6}$ IPSL, LOCEAN, Paris, France

$24{ }^{7}$ Departamento de Oceanografia Fisica, CICESE, Ensenada, Baja California, Mexico 


\section{Abstract}

26 In situ Sea Surface Salinity (SSS) observations showed an increase $>+0.5$ over the period 27 2002-2009 in the Gulf of Guinea, off the Niger Delta. Observed changes in the Niger River 28 runoff were not consistent with this increase in SSS, but the increase was reproduced in a 29 regional numerical simulation with climatological river runoff. The simulated mixed-layer 30 salinity budget was used to identify the mechanisms responsible for the increase. When 31 comparing the period 2002-2009 with the period 1993-2001, significant changes in the salt

32 budget were identified. The increase in SSS in the more recent period appeared to be driven 33 by changes in the atmospheric freshwater flux, mainly attributed to a regional decrease in 34 precipitation. Horizontal advection partly compensated for the effect of freshwater flux 35 through changes in zonal currents and zonal SSS gradients.

40 Keywords: Mixed-layer salt budget, Precipitation, SSS trend 
Introduction

Sea Surface Salinity (SSS) is a key indicator of changes in the hydrological cycle at

48 the ocean surface, where most of Earth's freshwater fluxes occur (Yu 2011). Quantifying

49 salinity variability is important, therefore, for understanding global climate change. Curry et

50 al. (2003) showed that SSS increased between the 1960s and the 1990s in the tropical and

51 subtropical North Atlantic, at a rate of 0.02 decade $^{-1}$. The authors suggested that this SSS

52 increase was caused by increased evaporation associated with global warming of the ocean.

53 Using in-situ observations, Boyer et al. (2005) found that, over the same four decades, the

54 Atlantic Ocean exhibited a large, positive salinity trend (exceeding 0.03 decade $^{-1}$ ) in the

55 subtropics and tropics in both the Northern and Southern hemispheres. Grodsky et al. (2006),

56 using a dataset combining the same historical data as the previous studies but with additional

57 data sources that extended to 2004, suggested that the near-surface waters in the tropical

58 Atlantic underwent a major salinification during the period 1960-1985 at a rate of 0.1 decade $^{-}$

$59^{1}$, followed by the reverse trend. Whereas they found that year-to-year changes in salinity

60 were related to precipitation, they attributed decadal salinity changes to wind changes in the

61 deep tropics altering upwelling intensity and, possibly, evaporation rates.

In this study, we use a new in situ SSS gridded dataset for the Atlantic basin (Da-

63 Allada et al. 2013) to show a recent increase in SSS in the Gulf of Guinea. This increase was

64 also present in a regional simulation of the Tropical Atlantic Ocean from an ocean general

65 circulation model (OGCM) (Jouanno et al 2013). We used the simulated mixed-layer salinity

66 (MLS) budget to identify the mechanisms responsible for this salinification.

67 We describe (1) the SSS data used in the study and the numerical model employed,

68 and (2) how the model was validated and how it explores changes in the salt budget,

69 freshwater flux and horizontal advection. 
Material and methods

\section{Data and model}

\section{In situ SSS dataset}

The observed-SSS product is an updated version of the dataset of Reverdin et al. (2007) described in Da-Allada et al. (2013). The monthly SSS are gridded using an objective mapping (Bretherton et al. 1976) at $1^{\circ} \times 1^{\circ}$ spatial resolution, by compiling a variety of data sources, primarily from underway thermosalinographs on research vessels and voluntary observing ships, from the Prediction and Research Moored Array in the Tropical Atlantic (PIRATA) moorings, from surface drifters and from Argo floats. Figure 1 shows the temporal and spatial resolution over the region $15^{\circ} \mathrm{N}-15^{\circ} \mathrm{S}, 20^{\circ} \mathrm{W}-15^{\circ} \mathrm{E}$ for the period $1993-2009$. The data distribution increased after 2005 as a result of the deployment of ARGO floats in the region. The overall density of observations presents a marked contrast between areas of poor data coverage (e.g. the south-east region of the Gulf of Guinea) and areas of high density that occur along well-used shipping lines. We chose this SSS product as a reference for model evaluation as it is, to our knowledge, the most complete and up-to-date SSS product available for the Tropical Atlantic basin; salinity has been measured using the pratical salinity scale.

\section{Model}

The model configuration is based on the Nucleus for European Modelling of the Ocean (NEMO) general ocean circulation modelling system (Madec 2008). It solves the three dimensional primitive equations in spherical coordinates discretised on a C-grid and fixed vertical levels. The model design is a regional configuration of the tropical Atlantic at $14^{\circ}$ horizontal resolution. There are 75 levels in the vertical, with 12 in the upper 20 meters and 24 in the upper 100 meters. The model is forced at its boundaries $\left(20^{\circ} \mathrm{S}-20^{\circ} \mathrm{N}\right.$ and $60^{\circ} \mathrm{W}$ $15^{\circ} \mathrm{E}$ ) using a radiative open boundary condition provided by outputs from the global interannual experiment ORCA025-MJM95 developed by the DRAKKAR team (Barnier et al. 
96 2006). The vertical turbulent mixing is parameterized using a level-1.5 turbulence closure

97 scheme, with a prognostic equation for turbulence kinetic energy (TKE) and a diagnostic

98 equation for length scale (Blanke and Delecluse 1993).

99 The atmospheric fluxes of momentum, heat and freshwater were provided by bulk

100 formulae (Large and Yeager 2004) and ERA-Interim reanalysis from the European Centre for

101 Medium-Range Weather Forecasts (ECMWF) (3-hour fields of wind, atmospheric

102 temperature and humidity, and daily fields of long and shortwave radiation and precipitation).

103 This product appears to be the most appropriate in terms of freshwater budget in the Tropical

104 Atlantic (Da-Allada et al. 2013). The short wave radiation forcing is modulated by a

105 theoretical diurnal cycle. A monthly climatology of continental runoffs from Dai and

106 Trenberth (2002) is prescribed near the rivers mouths as a surface freshwater flux. To justify

107 the use of monthly runoff, we tested different simulations (with climatology, yearly and

108 constant river flow) and found that interannual variability of river flow does not have much

109 effect on the interannual SSS in the eastern tropical Atlantic Ocean. It should be noted,

110 however, that uncertainty of the runoff data at interannual time scale is high in this region.

111 The model was initialized on 1 January 1990, using temperature and salinity outputs

112 from the ORCA025-MJM95 global experiment for the same date, and then integrated over the

113 period 1990-2009. Note that there was no restoring term toward a climatological SSS. Three

114 day averages values of SSS from 1993 to 2009 were used in the present analysis. Jouanno et

115 al. (2013) provide further details on the parameterization and some elements of validation,

116 including comparisons with surface and in-situ observations of temperature in the Gulf of

117 Guinea. Our focus was on the causes of salinification detected in the north-eastern part of the

118 Gulf of Guinea.

119 Salinity Budget 
121 in Ferry and Reverdin (2004), we used a salinity budget in the ocean mixed layer. This

122 approach has been widely used in the tropical Atlantic to investigate the processes controlling

123 the mixed-layer temperature at seasonal time scales (Peter et al. 2006).

124 Following the study of Vialard et al. (2001), the equation for mixed-layer salinity 125 evolution can be written as follows:

$\partial_{t} S S S=\underbrace{-\left\langle u \partial_{x} S\right\rangle}_{U A D V} \underbrace{-\left\langle v \partial_{y} S\right\rangle}_{V A D V} \underbrace{-\left\langle w \partial_{z} S\right\rangle}_{W A D V}+\underbrace{\left\langle D_{l}(S)\right\rangle}_{\text {DIFL }}-\underbrace{\frac{\left(k \partial_{z} S\right)_{z=-h}}{h}}_{\text {ZDF }}-\underbrace{\frac{1}{h} \frac{\partial h}{\partial t}\left(S S S-S_{z=-h}\right)}_{E N T}+\underbrace{\frac{(E-P-R) S S S}{h}}_{F W F}$

where $S$ is the model salinity, $u$ and $v$ are the eastward and northward components,

132 respectively, of the horizontal velocity, w is the upward vertical velocity, $\operatorname{Dl}(S)$ is the lateral

133 diffusion operator, $k$ is the vertical diffusion coefficient, $h$ is the time varying mixed-layer 134 depth, $E$ is evaporation, $P$ is precipitation and $R$ is river runoff.

The terms in Eq.1 represent, from left to right, mixed-layer salinity tendency,

136 horizontal advection ( $\mathrm{H} A D V ; \mathrm{H} A D V=\mathrm{U} A D V+\mathrm{V} A D V)$, vertical advection (W ADV),

137 horizontal diffusion (DIFL), vertical diffusion (ZDF) at the mixed-layer base, mixed-layer

138 salinity tendency due to variation of the mixed-layer depth, (ENT) and freshwater flux terms 139 (FWF).

140 The mixed-layer salinity budget was computed online to quantify precisely the

141 contributions of the different processes to the mixed-layer salinity tendency. The mixed layer

142 depth was defined by a density criterion $\left(0.03 \mathrm{~kg} \cdot \mathrm{m}^{-3}\right.$, de Boyer Montégut et al. 2004), in

143 order to take into account both temperature and salinity stratifications. As Foltz et al. (2004). 
144 We assumed that mixed-layer salinity is very close to SSS (Foltz et al. 2004). Therefore,

145 simulated mixed-layer salinity was compared to observed SSS to validate the model.

147 Results

\section{Model validation}

The model output of annual mean SSS for the period 1993-2009 was very similar to

150 the observed annual mean (Figure $2 \mathrm{a}-\mathrm{b}$ ). South of $5^{\circ} \mathrm{S}$, both the model output and the

151 observations showed high values of SSS in the subtropical gyre, which was probably the

152 result of intense evaporation in this region. Elsewhere, low SSS values are a result of either

153 the Intertropical Convergence Zone (ITCZ) along $5^{\circ} \mathrm{N}$, or the runoff from major rivers on the 154 west African coast (e.g. the Niger and Congo rivers, which are located in the vicinity of $5^{\circ} \mathrm{N}$ 155 and $5^{\circ} \mathrm{S}$ respectively).

With regard to the SSS seasonal cycle in the Gulf of Guinea, the model correctly

157 reproduced the amplitude and phase of the mixed-layer salinity. In particular, in the northern 158 region of the Gulf of Guinea, the use of an OGCM, which explicitly calculates vertical 159 diffusion, produced model output that more closely matched the observed values than did a 160 simplified mixed-layer model as used by Da-Allada et al. (2013), highlighting the important role of vertical diffusion in the Gulf of Guinea.

Observed and simulated linear trends in SSS are compared in Figure 2 c-d over the

163 period 2002-2009. The model exhibited a large, positive, salinity trend in the eastern tropical 164 Atlantic, with maximum values up to 0.8 occurring in the low salinity regions of the Gulf of 165 Guinea, i.e. off the Niger Delta and along the equator (Figure 2d). Negative salinity trends occurred in small regions, however. The map of the observed data (Figure 2c) shows regions

167 with negative trends (e.g. along the north coast of the Gulf of Guinea, which had negative 168 trends of around -0.2) and with positive trends (that were most prominent off the Niger Delta 
169 (0.8)) and less pronounced at the equator. Both observations and model results showed the 170 greatest increase near the Niger Delta $\left(1^{\circ} \mathrm{S}-5^{\circ} \mathrm{N}, 6^{\circ}-10^{\circ} \mathrm{E}\right)$ where the trend was significant

171 (Welch test; $\mathrm{p}<0.05$ ). Elsewhere trends are lower in amplitude and significance is 172 questionable. Therefore our analysis was focused on this region (see boxes in Figure 2 c-d), 173 referred to hereafter as the focal area.

174 Interannual SSS anomalies, spatially averaged in the focal area from both the 175 observations and the model output, are shown in Figure 3a. Both time series presented a 176 similar evolution, which showed two periods. The first period was characterized by an 177 absence of notable salinity trend in either the observations or the model output and was 178 termed the 'period of reference' (REF). The second exhibited a fairly large, positive SSS trend 179 of about +0.5 for the period 2002-2009 (Student's t-test; $\mathrm{p}<0.1$ ), in both the model output 180 and observations, and was termed the 'period of change' (CHA). The close agreement between 181 the modelled and observed SSS suggests that the model can be used to explore changes in the 182 salt budget responsible for the SSS increase.

183 Changes in salt budget Applying the model of Alory and Meyers (2009) to salinity, we compared the mean 185 balance of the salt budget between the periods REF and CHA to investigate possible changes. 186 Figure $3 \mathrm{~b}$ shows, for both periods and for both the model output and the observations: (1) 187 mean anomalies (and standard deviation) of SSS changes (dS); (2) linear trend of SSS; and 188 (3) the model salt budget terms, computed using a five-year running mean. The use of running 189 means allows the standard deviation to be estimated for each term, which assists with the 190 identification of significant changes in terms of the salt budget.

191 Change in SSS and the linear trend of SSS in the model were positive for the recent 192 period, CHA, and confirmed an SSS increase in the focal area, which was also detected in the 193 observations data (Figure 3b). In the model output, there was a significant change in SSS 
194 (Welch test; $\mathrm{p}<0.05$ ) between the two periods, REF and CHA. To identify the primary 195 mechanisms responsible for the SSS change, salinity balance terms were plotted in Figure 3b.

196 Horizontal diffusion and entrainment terms were negligible and were therefore not shown in 197 the figure. Freshwater flux (FWF) and horizontal advection (H ADV) changed significantly 198 (Welch test; $\mathrm{p}<0.05$ ). Freshwater flux was strongly negative during REF and became 199 strongly positive during CHA, which would explain the increase in SSS. Horizontal advection 200 was slightly positive during REF and became strongly negative during CHA. Hence it 201 contributed to decrease in SSS and tended to compensate for the effect of changes in 202 freshwater flux. Vertical advection (W ADV) and vertical diffusion (ZDF) also changed, but 203 not significantly.

\section{Changes in freshwater flux}

Likely causes of the change in freshwater flux were explored. Freshwater flux includes three components: evaporation $(\mathrm{E})$, precipitation $(\mathrm{P})$ and runoff $(\mathrm{R})$. Increasing SSS in the model was not related to a change in river runoff because only climatological run-off was

208 used in Eq.1. Moreover, the interannual variability of the Niger runoff, determined from 209 altimetry according to the method developed by Papa et al (2010), did not exhibit any 210 significant changes during the period 2003-2009, other than a slight increase in 2009 (data not 211 shown).

Mean evaporation from ERA-Interim and from the model (computed through bulk

213 formulae) are presented in Figure 4a-b. Evaporation values were high south of $5^{\circ} \mathrm{S}$ and low

214 elsewhere in the basin. Changes in evaporation between CHA and REF are shown in Figure

$2154 \mathrm{~d}$. Increase in evaporation was weak in the focal area as well as south of equator. The mean 216 contribution of evaporation to the salt budget $(\mathrm{ES} / \mathrm{H}$, where $\mathrm{S}$ is salinity and $\mathrm{H}$ is mixed-layer 217 depth) was positive (about $18 \mathrm{yr}^{-1}$; Figure 4e), with a pattern slightly different than that for 218 evaporation itself due to spatial variation in the mixed-layer depth (data not shown). The 
219 changes in ES/H between the two periods, CHA and REF, were positive (+1) in the focal area

220 (Figure 4f), indicating that changes in evaporation contributed only slightly to the increase in 221 SSS in recent years . ERA-Interim precipitation was at a maximum at around $5^{\circ} \mathrm{N}$ due to the ITCZ, and 223 weakened on either side of the ITCZ (Figure 4c). There was a large precipitation decrease 224 between the two periods in our focal area. Precipitation changes over the ocean seem to be linked to precipitation changes over the continent, with a deficit in precipitation around $10^{\circ} \mathrm{N}$ and an increase south of $5^{\circ} \mathrm{N}$, centred on $12^{\circ} \mathrm{E}$ (Figures $4 \mathrm{c}$ and $4 \mathrm{~g}$ ). However, rainfall products 227 are subject to uncertainties. Comparing of ERA-Interim with GPCP (Global Precipitation 228 Climatology Project) version 2.1 (Adler et al., 2003), based on observations, showed some 229 differences, especially on land. However, both products showed a decrease in precipitation in 230 the focal area (Figure 5a) although it was more pronounced in ERA-Interim. The higher231 resolution TRMM-3B43 satellite product (Adler et al., 2000) is limited to a shorter period that 232 which precluded a direct comparison between the CHA and REF periods, but there appeared 233 to be negative precipitation trend over the period 1998-2010 in the same focal area (Figure $2345 b$ ), which is consistent with changes in other products and tends to support our results. The mean contribution of precipitation to the salt budget was negative (-PS/H; $-30 \mathrm{yr}^{-}$

$236^{1}$ ), with a spatial pattern very similar to that for precipitation (Figure $4 \mathrm{~h}$ ). The change in this 237 term between the two periods, $\mathrm{CHA}$ and REF, was positive $(+3)$ in the focal area, suggesting 238 that its contribution increased SSS in the salt budget.

239 Hence it appears that, off the Niger Delta in recent years, precipitation decrease was 240 the dominant term with regard to freshwater-flux, and its contribution to the salt budget led to 241 an increase in SSS.

\section{Changes in horizontal advection}


244 delta changed significantly between the two periods, and tended to decrease SSS in the recent

245 period (Figure 3b), partly compensating the salinification effect of the freshwater fluxes. The

246 mean horizontal advection also contributed to a decrease in SSS in the whole basin (Figure

247 6a). Changes in horizontal advection had both positive and negative values, depending on 248 regions (Figure 6b), but, on average, were negative in the focal area. This was due mainly to 249 changes in zonal advection because changes in meridional advection contributed only slightly 250 to an increase in SSS (data not shown).

251 To identify whether changes in zonal currents or zonal SSS gradients were responsible

252 for the changes in $\mathrm{H} \mathrm{ADV}$, the mean zonal current, changes in zonal current, mean zonal SSS 253 gradient and changes in zonal SSS gradient were mapped (Figure 6). In the Gulf of Guinea, 254 the mean zonal SSS gradient is mainly negative over the basin, as SSS weakens towards the 255 African coast, and the mean current system consists of the eastward flowing Guinea Current 256 (GC) along the northern coast of the Gulf of Guinea and the westward flowing South 257 Equatorial Current (SEC), with its two branches located on each side of the equator. The 258 model suggests that the strength of both GC and SEC increased in the recent years. In the 259 focal area, comparison between the two periods showed weakening eastward flow and 260 strengthening westward flow, in addition to a mean negative SSS gradient. This contributed to 261 the negative advection term, which partly compensated for the freshwater flux contribution.

\section{Discussion}

Interannual variations of SSS during the period 1993-2009 were analysed using a

264 regional numerical simulation and observations. Both model and observations showed a 265 positive, linear trend of SSS since 2002 in the Gulf of Guinea, specifically in a focal area near 266 the mouth of the Niger River delta. The interannual SSS anomalies spatially averaged in this 267 region can be split into two periods: a period of reference (1993-2001), in which SSS was 
stable, and a period of change (2002-2009), in which SSS increased significantly. Hosoda et al

269 (2009), when comparing SSS in the world ocean between the period 2003-2007 and the

270 period 1960-1989, also found positive salinity anomalies in the eastern part of the Gulf of

271 Guinea (which were actually the largest in the tropical Atlantic, see their figure 1c), which is

272 consistent with our findings.

We used a simulated mixed-layer salinity budget to identify the changes in the salt

274 budget by comparing the mean balance of the salt budget between the two periods. We have

275 found that SSS increases significantly in the model. In the salt budget, only freshwater flux

276 and horizontal advection changed significantly. Freshwater flux was strongly positive in the

277 recent period, explaining the increase in SSS. Horizontal advection was strongly negative

278 during this period and acted to compensate partially for the effect of freshwater flux. The

279 remaining salt balance terms did not change significantly.

280 We investigated the causes of these significant changes in freshwater flux and

281 horizontal advection. SSS increase was not related to changes in rivers runoff as we used

282 climatological river runoff in the simulation. Changes in freshwater flux were mainly due to

283 decreasing precipitation in the focal area. These local changes in precipitation may have been

284 related to changes in continental precipitation in neighboring areas. In their investigation of

285 SSS differences between the 1960s and the 1990s at a large spatial scale in the tropical

286 Atlantic, Curry et al. (2003) and Grodsky et al. (2006) also found that atmospheric freshwater

287 fluxes contributed to an increase SSS. In our study, changes in both zonal current and in zonal

288 SSS gradient led to significant changes in horizontal advection. Hence we conclude that this

289 effect dominates the ocean processes and tends to attenuate the effect of freshwater changes.

290 Grodsky et al. (2006) had previously noted a salinification in the Gulf of Guinea but of

291 a smaller than that found in the current study, probably because they considered a larger

292 region and longer period (1960-1999). Grodsky et al. (2006) also noted a decadal variability 
293 in SSS in addition to an increasing salinity trend in this region, but we cannot conclude if the

294 trend found in our study was part of a decadal signal of SSS or a signature of a longer-time 295 trend. Interestingly, a global analysis also suggested that some of the largest increase in SSS 296 over the period 1950-2008 were found in the Gulf of Guinea (Durack and Wijffels, 2010).

297 Whereas at large scales the hydrological cycle is expected to strengthen in a warming climate 298 and consequently decrease salinity in the wet tropics (Terray et al. 2012), the observed 299 salinification in the Gulf of Guinea suggests that regional changes are driven by more 300 complex processes. The recently available satellite products for SSS (SMOS, Aquarius; 301 Lagerloef 2012; Reul et al. 2012) and the recent increases in ARGO observations in the Gulf 302 of Guinea, will be useful to better understand these processes.

\section{Acknowledgments}

The SSS data were extracted from the French SSS observation service, available at

307 http://www.legos.obs-mip.fr/observations/sss. We acknowledge the provision of

308 supercomputing facilities by the CICESE. We acknowledge the PIRATA Project and TAO 309 Project Office at NOAA/PMEL for providing open access to PIRATA data. The regional 310 configuration was set up in cooperation with the DRAKKAR project (http://www.drakkar311 ocean.eu/). Special thanks are due to Fabien Durand and Frédéric Marin for interesting and 312 fruitful discussions and to Fabrice Papa for computing satellite derived Niger runoff in the 313 recent period. C.Y. D-A would like to thanks the SCAC of the French Embassy in Cotonou, 314 Bénin, and IRD for their support through PhD grants. The authors wish to thank TOTAL S.A. 315 for supporting ICMPA-UNESCO Chair where this work was completed. 


\section{References}

317 Adler RF, Huffman GJ, Bolvin DT, Curtis S, Nelkin EJ. 2000. Tropical rainfall distributions determined using TRMM combined with other satellite and rain gauge information. Journal of Applied Meteorology 39(12): 2007-2023.

Adler RF, Huffman GJ, Chang A, Ferraro R, Xie P, Janowiak J, Rudolf B, Schneider U, Curtis S, Bolvin D, Gruber A, Susskind J, Arkin P. 2003. The Version 2 Global Precipitation Climatology Project (GPCP) Monthly Precipitation Analysis (1979Present). Journal of Hydrometeorology, 4:1147-1167.

Alory G, Meyers G. 2009. Warming of the Upper Equatorial Indian Ocean and Changes in the Heat Budget (1960-99). Journal of Climate, doi: 10.1175/2008JCLI2330.1.

Barnier B, Madec G., Penduff T, Molines JM, Tréguier AM, Beckmann A, Biastoch A, M, Mc Lean J. 2006. Impact of partial steps and momentum advection schemes in a global ocean circulation model at eddy permitting resolution. Ocean Dynamics 56: 543567.

Blanke B, Delecluse P. 1993. Variability of the tropical Atlantic Ocean simulated by a general circulation model with two different mixed-layer physics. Journal of Physical Oceanography 23: 1363-1388.

Boyer TP, Levitus S, Antonov JI Locarnini RA, Gracia HE. 2005. Linear trends in salinity for the World Ocean, 1955- 1998. Geophysical Research Letter 32: L01604, doi: 10.1029/2004GL021791.

Bretherton FP, Davis RE, Fandry CB. 1976. A technique for objective mapping and design of oceanographic experiments. Deep Sea Research 23: 559-582.

339 Curry R, Dickson R, Yashayaev I. 2003, Ocean evidence of a change in the fresh water balance of the Atlantic over the past four decades. Nature 426: 826-829. 
341 Da-Allada YC, Alory G, du Penhoat Y, Kestenare E, Durand F, Hounkonnou MN. 2013. 342 Seasonal mixed-layer salinity balance in the Tropical Atlantic Ocean: Mean sate and seasonal cycle. Journal of Geophysical Resesearch 118: doi: 10.1029/2012JC008357.

344 Dai A, Trenberth K. 2002. Estimates of freshwater discharge from continents: latitudinal and seasonal variations. Journal of Hydrometeorology, 3: 660-687.

346 De Boyer Montégut C, Madec G, Fischer AS, Lazar A, Ludicone D. 2004. Mixed layer depth over the global ocean: An examination of profile data and a profile-based climatology. Journal of Geophysical Research-Oceans, 109: (C12), 52-71.

Durack PJ, Wijffels SE. 2010. Fifty-year trends in global ocean salinities and their relationship to broad-scale warming. Journal of Climate 23: 4342-4362, doi: 10.1175/2010JCLI3377.1.

352 Ferry N, Reverdin G. 2004. Sea surface salinity interannual variability in the western tropical Atlantic: An Ocean general circulation model study. Journal of Geophysical Research 109, DOI 10.1029/2003JC002122. 109: C03052, doi: 10.1029/2003JC002111.

Grodsky, SA, Carton JA, Bingham FM. 2006. Low frequency variation of sea surface salinity in the tropical Atlantic, Geophysical Research Letter 33: L14604, doi: 10.1029/2006GL026426.

Hosoda S, Suga T, Shikama N, Mizuno K. 2009. Global surface layer salinity change detected by Argo and its implication for hydrological cycle intensification. Journal of Oceanography, 65, 579-586. 
Jouanno J, Marin F, du Penhoat Y, Sheinbaum J, Molines JM. 2013. Intraseasonal modulation of the surface cooling in the Gulf of Guinea. Journal of Physical Oceanography, doi:10.1175/JPO-D-12-053.1

Large W, Yeager S. 2004. Diurnal to decadal global forcing for ocean sea ice models: The data sets and flux climatologies. Rep. NCAR/TN-460+STR, Natl. Cent. For Atmos. Res., Boulder, Colorado.

Madec G. 2008. « NEMO ocean engine ». Note du pole de modélisation, Institut Pierre-Simon Laplace (IPSL), Paris.

Papa F, Durand F, Rossow WB, Rahman A, Bala SK. 2010. Satellite altimeter- derived monthly discharge of the Ganga - Brahmaputra River and its seasonal to interannual variations from 1993 to 2008. Journal of Geophysical Research 115: C12013, doi: $10.1029 / 2009 J C 006075$.

Peter AC, Le Hénaff M, du Penhoat Y, Menkes CE, Marin F, Vialard J, Caniaux G, Lazar A. 2006. A model study of the seasonal mixed-layer heat budget in the equatorial Atlantic. Journal of Geophysical Research 111: C06014, doi: 10. 1029/2005JC003157.

Reverdin G, Kestenare E, Frankignoul C, Delcroix T. 2007. In situ surface salinity in the tropical and subtropical Atlantic Ocean. Part I. Large scale variability. Progress in Oceanogry 73 (3), 311-340. http://dx.doi.org/10.1016/j.pocean.2006.11.004.

Terray L, Corre L, Cravatte S, Delcroix T, Reverdin G, Ribes A. 2012. Near-Surface Salinity as Nature's Rain Gauge to Detect Human Influence on the Tropical Water Cycle. Journal of Climate 25: 958-977, doi: 10.1175/JCLI-D-10-05025.1.

Vialard J, Menkes C, Boulanger JP, Delecluse P, Guilyardi E (2001) A model study of oceanic 86 mechanisms affecting equatorial Pacific sea surface temperature during the 1997-1998. EL Nino. Journal of Physical Oceanography., 31 1649-1675. 
388 Yu L. 2011. A global relationship between the ocean water cycle and near surface salinity. 


\section{Figure Captions:}

391 Figure 1. Sea surface salinity data distribution indicating the number of $1^{\circ} \times 1^{\circ}$ grid points

392 with data in a month as a function of year (top panel). Spatial distribution of the number of 393 months with data in $1^{\circ} \times 1^{\circ}$ box for 1993 - 2009 (bottom panel).

394 Figure 2. Annual mean sea surface salinity (SSS) for (a) observations and (b) model ; mean 395 linear trend of SSS build from a 5-year running mean over the period 2002-2009 for (c) 396 observations and (d) model.

397 Figure 3. (a) Time series interannual anomalies of SSS: Observations (black), model (red), 398 model trend (dashed blue) and observation trend (dashed purple) for the period REF, and the 399 model trend (blue) and observation trend (purple) for the period CHA. Time series are 400 averaged over the focal area $\left(1^{\circ} \mathrm{S}-5^{\circ} \mathrm{N}, 6^{\circ}-10^{\circ} \mathrm{E}\right)$. The mean seasonal cycle is removed and a 401 1-year running mean is applied; (b) SSS changes and SSS trend in model and observation 402 (respectively dS M, trend $\mathrm{M}$, dS O and trend $\mathrm{O}$ ), and model salt budget terms, averaged over 403 the study box (FWF: freshwater fluxes; H ADV: horizontal advection; W ADV: vertical 404 advection; ZDF: vertical diffusion). A 5- year running mean anomalies for the period of 405 reference (REF) is in blue and the period of change (CHA) is in red.

406 Figure 4. Annual mean for (a) model evaporation (in mm.day ${ }^{-1}$ ), (b) ERA Interim 407 evaporation (in mm.day ${ }^{-1}$ ); (c) ERA Interim precipitation ((in mm.day ${ }^{-1}$ ); (d) changes in 408 model evaporation (in $\mathrm{mm}$ ); (e) annual mean contribution to the salt budget for ES/H (E 409 evaporation, S salinity, H mixed layer depth); (f) Changes in ES/H; (g) Changes in ERA410 Interim precipitation (in $\mathrm{mm}$ ); (h) annual mean contribution to the salt budget for $-\mathrm{PS} / \mathrm{H}(\mathrm{P}$ 411 precipitation); (i) changes in $-\mathrm{PS} / \mathrm{H}$.

412 Changes are calculated between the period of change (CHA) and the period of reference 413 (REF) build using a 5-year running window. Changes in precipitation and evaporation are 
414 calculated using cumulative values for each period. Wind vectors (c) and wind changes 415 vectors (values multiplied by 5$)(\mathrm{g})$ are in $\mathrm{m} / \mathrm{s}$.

416 Figure 5. a) Changes in GPCP precipitation between CHA and REF periods (in mm) and b) 417 Linear trend over the 1998-2010 period in TRMM-3B43 precipitation (in mm/day/year). The 418 region of study is indicated.

419 Figure 6. Horizontal advection annual mean (a) and changes (b); zonal current annual mean 420 (c) and changes (d) in $\mathrm{ms}^{-1}$; zonal SSS gradient annual mean (e) and changes (f) in $\mathrm{m}^{-1}$. 421 Changes are the difference between the period of change (CHA) and the period of reference 422 (REF) build using a 5-year running window. 

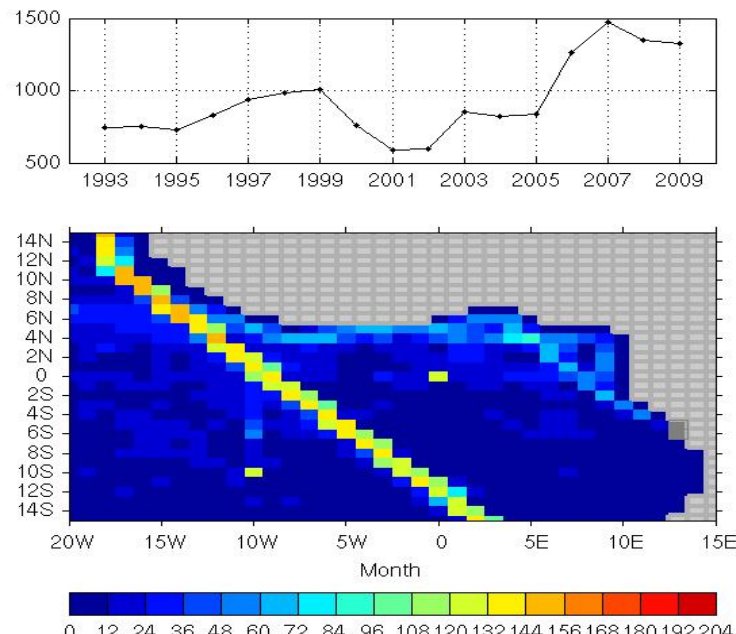

426 Figure 1: Sea surface salinity data distribution indicating the number of $1^{\circ} \times 1^{\circ}$ grid points

427 with data in a month as a function of year (top panel). Spatial distribution of the number of 428 months with data in $1^{\circ} \times 1^{\circ}$ box for 1993 - 2009 (bottom panel). 

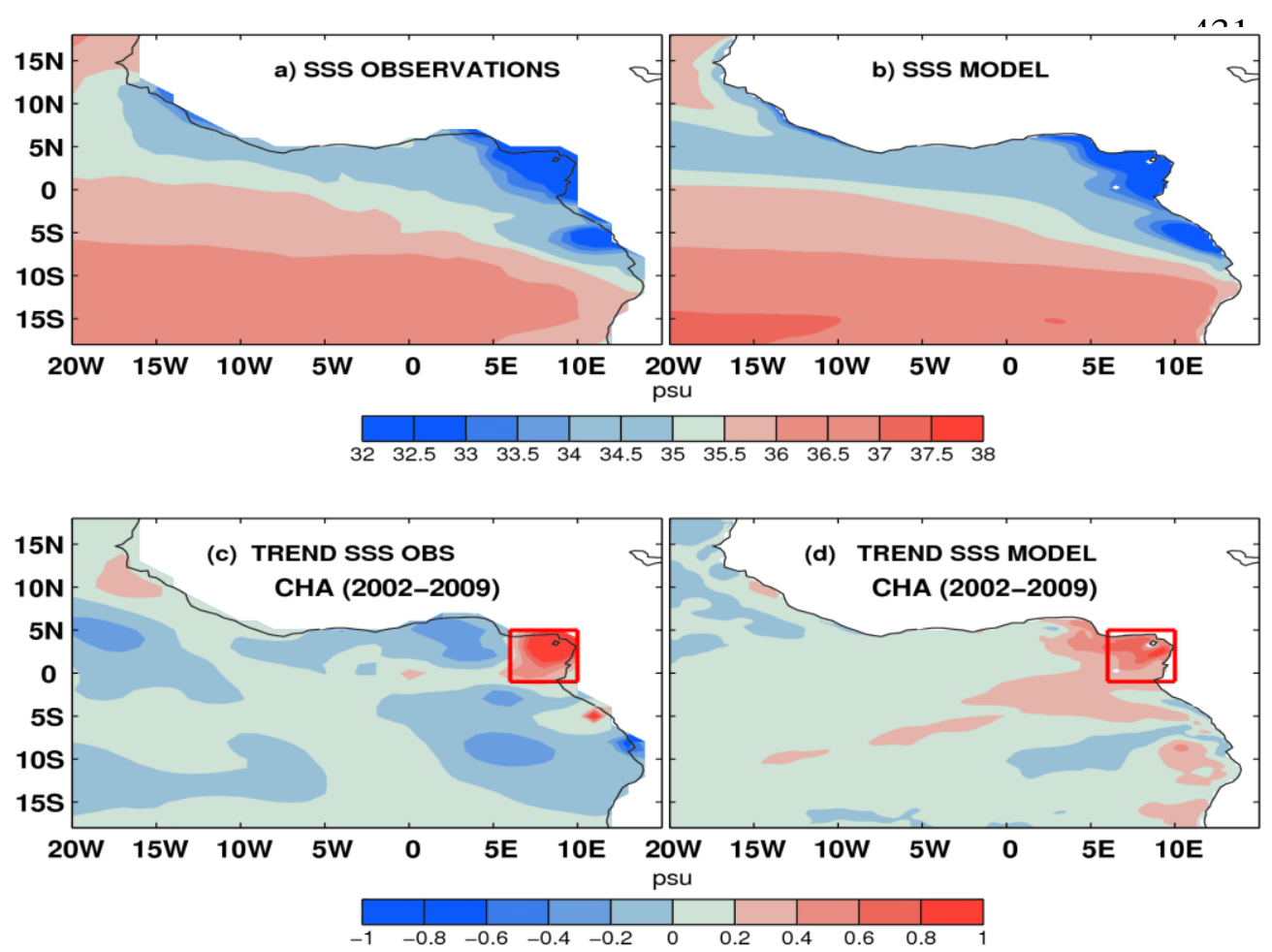

442 Figure 2. Annual mean sea surface salinity (SSS) for (a) observations and (b) model ; mean

443 linear trend of SSS build from a 5-year running mean over the period 2002-2009 for (c)

444 observations and (d) model. 


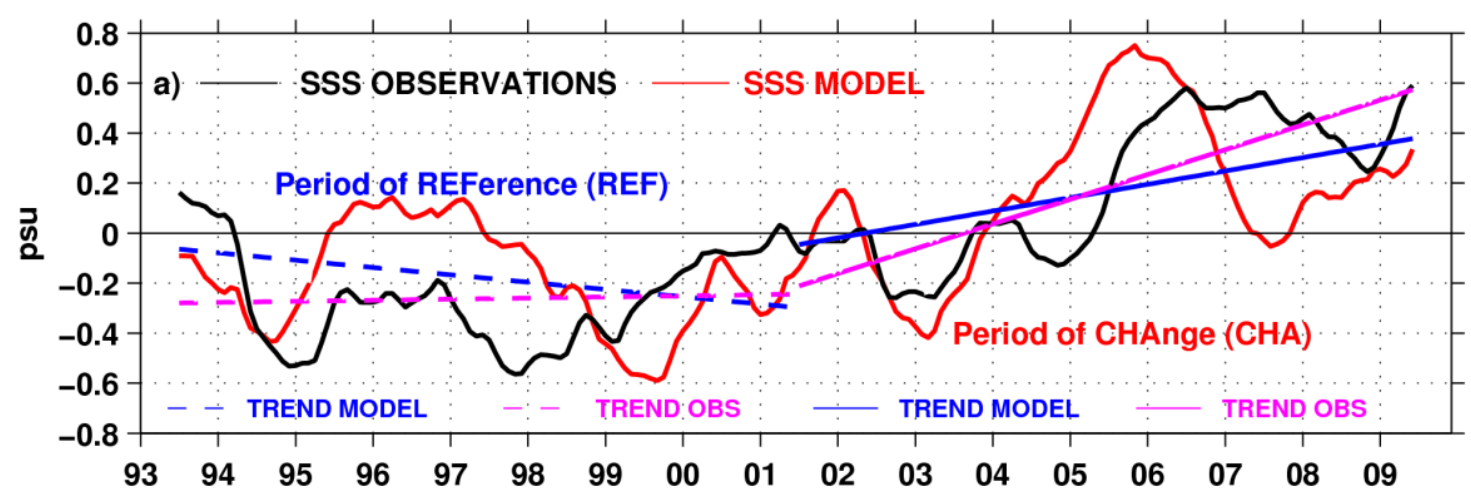

b) 5-years running means anomalies terms of dS averaged over the box

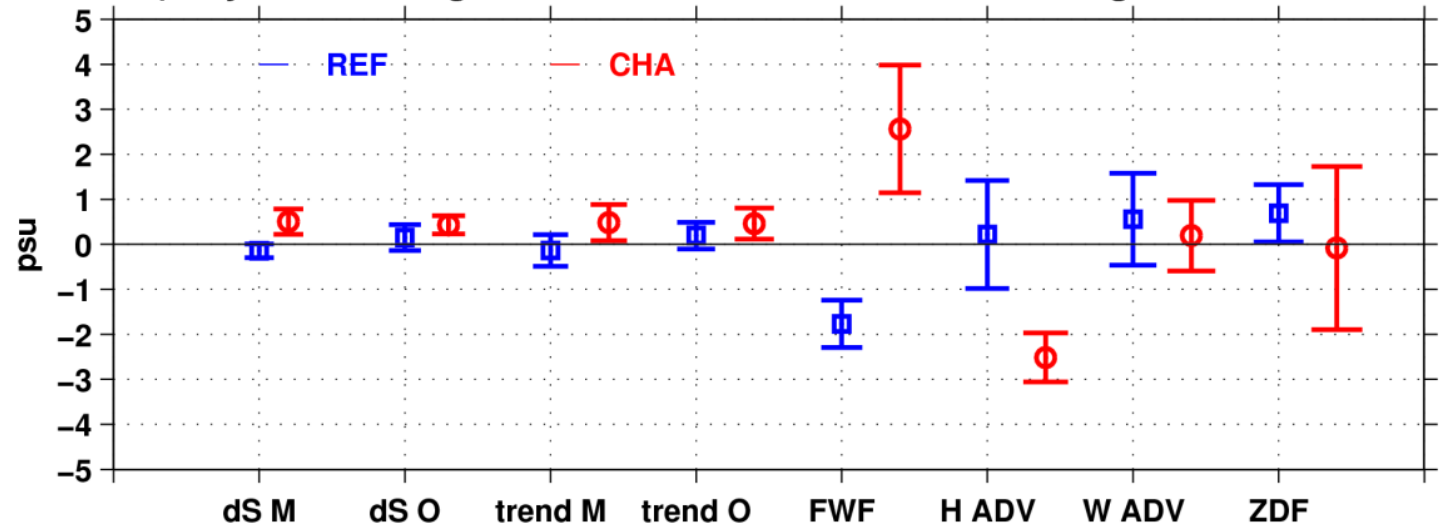

451 Figure 3. (a) Time series of SSS interannual anomalies: Observations (black), model (red),

452 model trend (dashed blue) and observation trend (dashed purple) for the period REF, and the

453 model trend (blue) and observation trend (purple) for the period CHA. Time series are 454 averaged over the study box $\left(1^{\circ} \mathrm{S}-5^{\circ} \mathrm{N}, 6^{\circ}-10^{\circ} \mathrm{E}\right)$. The mean seasonal cycle is removed and a 455 1-year running mean is applied; (b) SSS changes and SSS trend in model and observation 456 (respectively dS M, trend $\mathrm{M}$, dS O and trend $\mathrm{O}$ ), and model salt budget terms, averaged over 457 the study box (FWF: freshwater fluxes; H ADV: horizontal advection; W ADV: vertical 458 advection; ZDF: vertical diffusion). A 5- year running mean anomalies for the period of 459 reference (REF) is in blue and the period of change (CHA) is in red. Units are psu. 


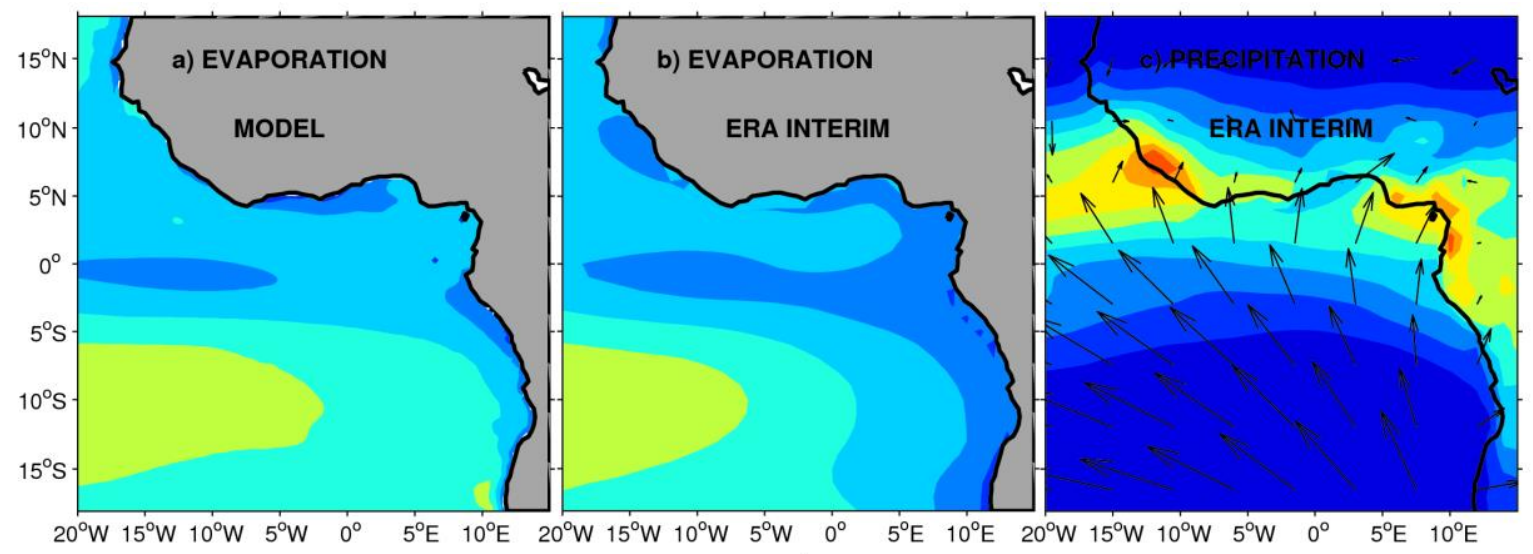

mm.day ${ }^{-1}$
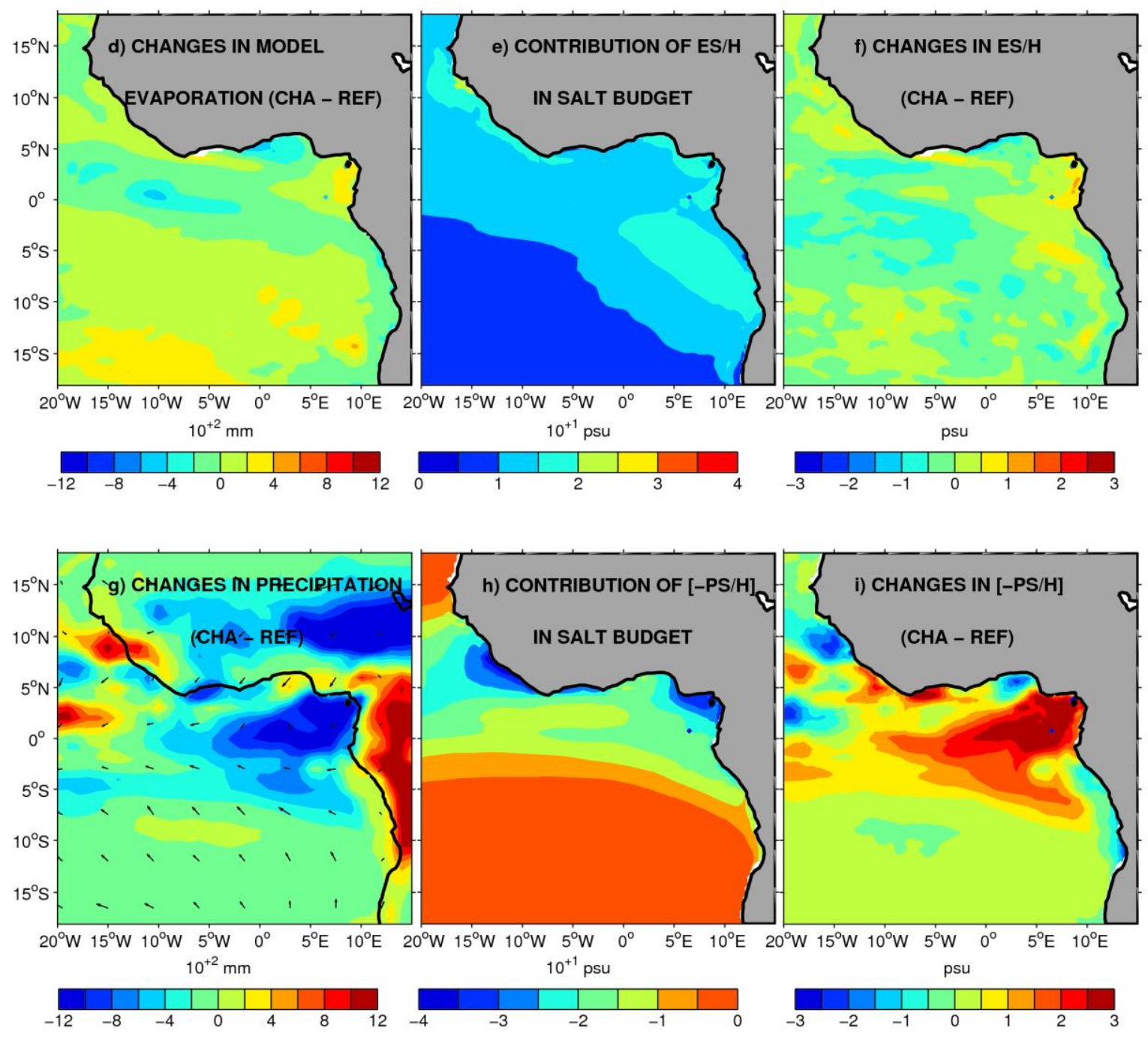

463 Figure 4. Annual mean for (a) model evaporation (in mm.day ${ }^{-1}$ ), (b) ERA Interim

464 evaporation (in mm.day ${ }^{-1}$ ); (c) ERA Interim precipitation ((in mm.day ${ }^{-1}$ ); (d) changes in 
465 model evaporation (in $\mathrm{mm}$ ); (e) annual mean contribution to the salt budget for $\mathrm{ES} / \mathrm{H}$ (E 466 evaporation, S salinity, H mixed layer depth) (in psu); (f) Changes in ES/H; (g) Changes in 467 ERA-Interim precipitation (in $\mathrm{mm}$ ); (h) annual mean contribution to the salt budget for $468 \mathrm{PS} / \mathrm{H}$ ( $\mathrm{P}$ precipitation); (i) changes in $-\mathrm{PS} / \mathrm{H}$. ES/H and $\mathrm{PS} / \mathrm{H}$ are the contributions of 469 evaporation and precipitation respectively to the salinity balance.

470 Changes are calculated between the period of change (CHA) and the period of reference 471 (REF) build using a 5-year running window. Changes in precipitation and evaporation are 472 calculated using cumulative values for each period. Wind vectors (c) and wind changes 473 vectors (values multiplied by 5) (g) are in $\mathrm{m} / \mathrm{s}$.

474

475

476 


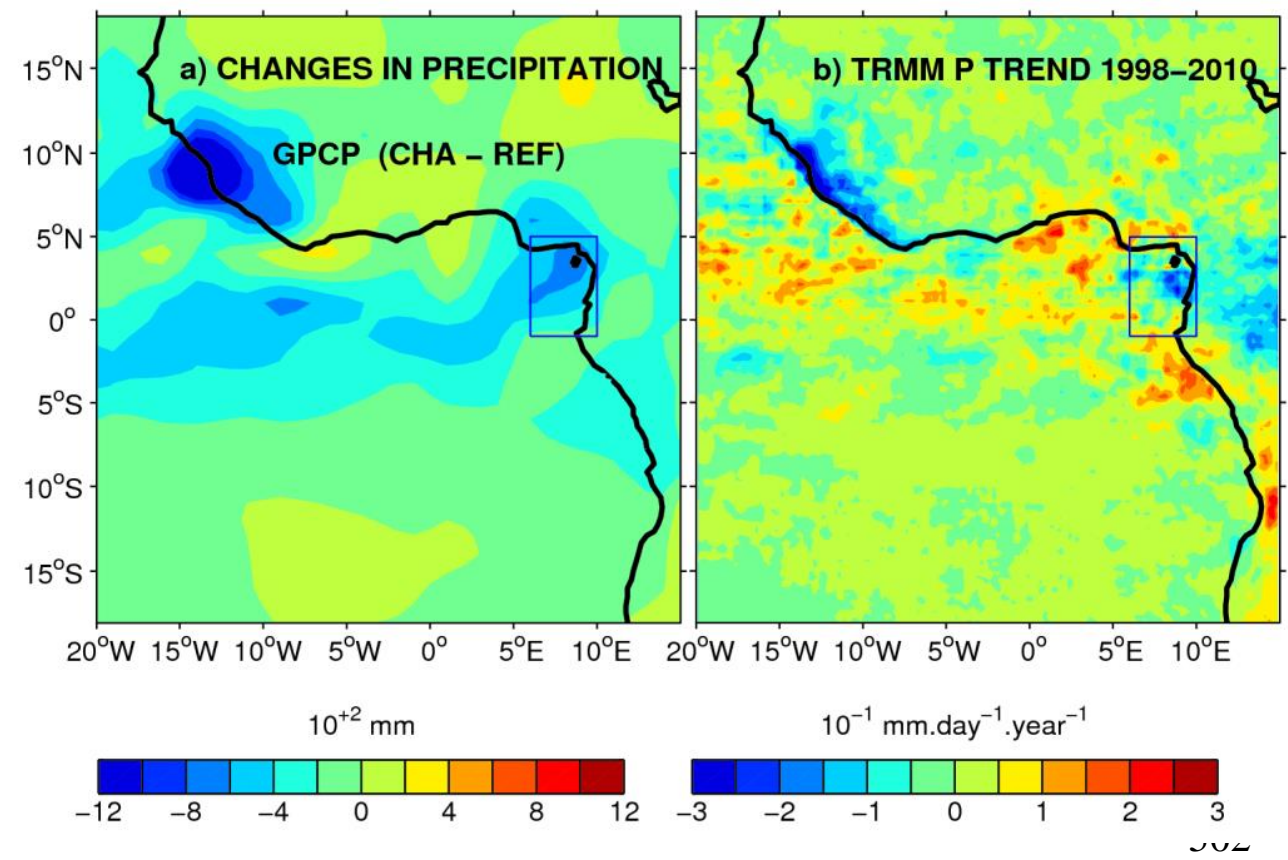

503 Figure 5. a) Changes in GPCP precipitation between CHA and REF periods (in mm) and b)

504 Linear trend over the 1998-2010 period in TRMM-3B43 precipitation (in mm/day/year). The 505 region of study is indicated.

506 

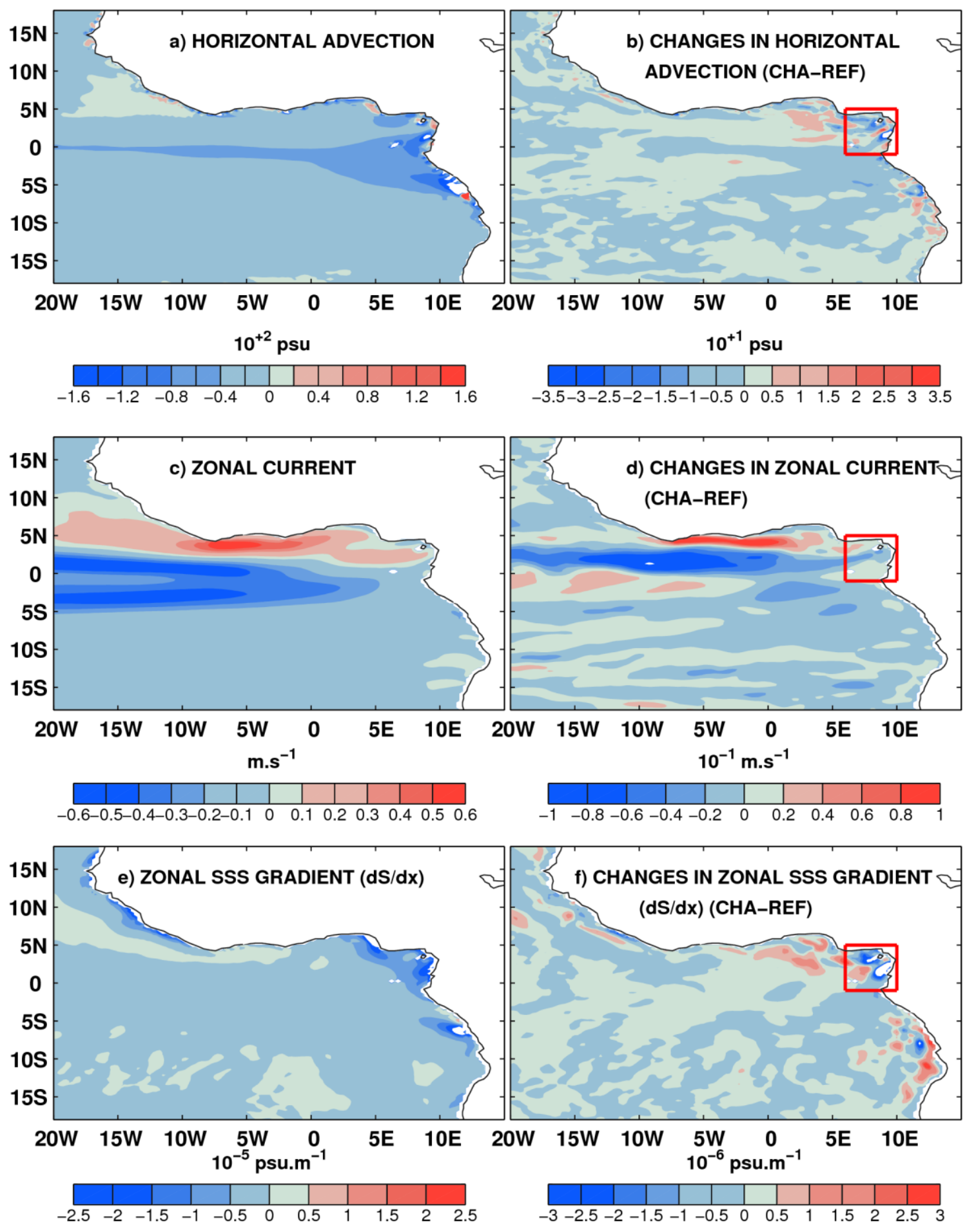

510 Figure 6. Horizontal advection annual mean (a) and changes (b) in psu; zonal current annual

511 mean (c) and changes (d) in $\mathrm{ms}^{-1}$; zonal SSS gradient annual mean (e) and changes (f) in 
512 psu.m ${ }^{-1}$. Changes are the difference between the period of change (CHA) and the period of 513 reference (REF) build using a 5-year running window.

514 